\title{
POTENTIAL OF Syncephalastrum racemosum AND Rhizopus arrhizus ISOLATED FROM OIL PALM TRUNKS PRODUCE CHITOSANS THAT INHIBIT THE GROWTH OF Ganoderma boninense
}

\section{FAHRIZAL, $M^{*} ;$ SARIFUDDIN ${ }^{*}$ and SABRINA, $T^{\star}$}

\begin{abstract}
Chitosan has been proposed as a treatment to suppress Ganoderma infection on oil palm. Syncephalastrum racemosum and Rhizopus arrhizus, growing on oil palm trunk, were examined on their ability to produce chitosan. Chitinous materials from both fungi were deproteinised and deacetylated using different concentrations of sodium hydroxide $(\mathrm{NaOH})$. Chitosans from R. arrhizus ( $F u C s R a)$, S. racemosum ( $\mathrm{FuCsSr}$ ) were compared with crab shells' chitosan ( $\mathrm{CrCs}$ ) through the Fourier-transform infrared spectroscopy (FTIR) analysis. The deacetylation degrees of different chitosan sources were also determined. FTIR analysis showed that chitosans produced by these fungi and crab shell's chitosan had a similar pattern of FTIR spectrum, but differed in their deacetylation degrees. The next experiment examined the ability of these chitosans to suppress the growth of Ganoderma boninense (G. boninense) in vitro. The experiment consisted of 11 treatments: controls, media with CrCs (at 5000, 7500, 10000 ppm), media with FuCsRa (at 5000, 7500, 10000 ppm), media with FuCsSr (at 5000, 7500, 10000 ppm) and antagonistic test (S. racemosum; R. arrhizus). The results showed that CrCS at 5000, 7500 and 10000 ppm enhanced the growth of G. boninense. A concentration of 10000 ppm of $\mathrm{CrCs}$ nearly doubled the growth of Ganoderma compared to control. FuCsSc inhibited the growth of G. boninense at all concentrations from -28\% to $31 \%$ compared to control. The in vitro antagonistic effect of S. racemosum showed a high effect at inhibiting the growth of G. boninense (-43\% compared to control). This in vitro study demonstrated the ability of chitosan extracted from fungi growing on oil palm trunks to suppress Ganoderma growth.
\end{abstract}

\section{Keywords: chitosan, crab shells, Ganoderma boninense, oil palm trunk fungus.}

Received: 22 March 2019; Accepted: 27 July 2020; Published online: 11 September 2020.

\section{INTRODUCTION}

Ganoderma boninense (G. boninense) is a lethal disease that affects the growth of oil palm trees. It is a severe disease in oil palm plantations in North Sumatra, Indonesia, as Ganoderma attacks can be severe and harmful. When Ganoderma infects a young oil palm, its growth may be severely affected and may lead to its death. Oil palm farmers have tried various products to control the problem. Many

Faculty of Agriculture, University of Sumatera Utara,

Medan-20155 Indonesia.

E-mail: t.sabrina@usu.ac.id commercial products were offered with the promise of controlling Ganoderma. However, there is no scientific study on the efficacy of such products. One belief among oil palm growers is that chitosan can suppress Ganoderma attacks.

Chitosan is a biopolymer that has a similar structure to cellulose and can form a membrane. Chitosan has a hydroxyl and amino reactive group which allows it to be chemically modified, such as membrane. Chitosan can be found in nature, at the exoskeleton of crustaceans, mollusks, annelids, coelenterates and insects. Some fungi have the potential to produce chitosan. The fungus Syncephalastrum racemosum was found to produce 
the highest concentration of chitosan $\left(152 \mathrm{mg} \mathrm{g}^{-1}\right.$ mycelium) compared to nine other strains (Amorim et al., 2003). Rhizopus arrhizus SIS 30 can produce chitosan as much as $12.56 \mathrm{mg} \mathrm{g}^{-1}$ mycelium, which is below the production of chitosan from Cunningamella elegans SIS 41 (15.63 $\mathrm{mg} \mathrm{g}^{-1}$ mycelium) (Berger et al., 2018). A study has found that the addition of chitosan to artificial media could inhibit the growth of phytopathogenic Colletotrichum species (Berger et al., 2018).

Sabrina et al. (2018) found that $S$. racemosum and $R$. arrhizus can be isolated from chipped oil palm trunks. This study aimed to measure the ability of these two fungi to produce chitosan and investigate if they can be used to inhibit the growth of Ganoderma.

\section{MATERIALS AND METHODS}

\section{Experimental Site and Treatment Application}

This study was conducted at the University of Sumatera Utara from March to November 2018. Rhizopus arrhizus strains ATCC 111450, and Syncephalastrum racemosum isolates VPCI 1857/11 (identified using DNA marker) were isolated from pieces of oil palm trunk from Labuhan Batu district in North Sumatera Province, Indonesia. The trunk has $\mathrm{C}=29.64 \%, \mathrm{~N}=0.53 \%$ and $\mathrm{C} / \mathrm{N}=55.9$ (Sabrina et al., 2018). Crab shells were obtained from a crab farm in Langkat district. G. boninense was from the plant protection laboratory collection of the Faculty of Agriculture, University of Sumatera Utara.

\section{Extraction of Chitosan and Analysis}

The preparation began with washing of the raw crab shell waste with water repeatedly. The shell was dried under the sun until it was completely dry. The dried shell was ground with an electric blender and passed through 50 mesh sieves. The crab shell powder that passed through the 50 mesh sieve was dried in an oven at $60^{\circ} \mathrm{C}$ for $6 \mathrm{hr}$. Extraction of chitosan from the crab shells included deproteinisation with $4 \%(\mathrm{w} / \mathrm{v})$ sodium hydroxide $(\mathrm{NaOH})\left(1: 10,80^{\circ} \mathrm{C} 1\right.$ $\mathrm{hr}$ ), demineralisation with $150 \mathrm{ml} 1 \mathrm{M}$ hydrochloric acid $(\mathrm{HCl})(1: 15)$, depigmentation with $4 \%(\mathrm{w} / \mathrm{v})$ sodium chloride $(\mathrm{NaCl})$, deacetylation $40 \%(\mathrm{w} / \mathrm{v})$ $\mathrm{NaOH}\left(1: 15,80^{\circ} \mathrm{C} 1 \mathrm{hr}\right)$.

Isolated $R$. arrhizus and $S$. racemosum were cultivated on Patato Dextrose Agar (PDA) at $28^{\circ} \mathrm{C}$ for seven days. A suspension of each strain was prepared and adjusted to contain $10^{7}$ sporangioles $\mathrm{ml}^{-1}$ using a hemocytometer. A $1 \mathrm{ml}$ suspension was inoculated to sterile petri dishes containing PDA and maintained for $24 \mathrm{hr}$ at $28^{\circ} \mathrm{C}$. Cultures were sub-cultured on PDA plates, incubated at $28^{\circ} \mathrm{C}$ for seven days, then cultivated in liquid PDA separately. Mycelia from both fungi were harvested by filtration, washed with distilled water and freezedried. The dry weight obtained for $S$. racemosum was

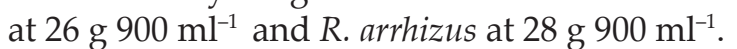

The chitosan from 3-10 g lyophilised mycelia was isolated following the procedures of Synowiecki and Al-Khateeb (1997). The overall process involved: deproteinisation with $2 \% \mathrm{w} / \mathrm{v}$ $\mathrm{NaOH}$ solution $\left(30: \mathrm{lv} / \mathrm{w} ; 90^{\circ} \mathrm{C}, 2 \mathrm{hr}\right)$, separation of the alkali-insoluble fraction (AIF) by centrifugation (4000 x g, $15 \mathrm{~min}$ ), extraction of chitosan from AIF under reflux $\left(10 \% \mathrm{v} / \mathrm{v}\right.$ acetic acid, $40: 1 \mathrm{v} / \mathrm{w}, 60^{\circ} \mathrm{C}$, $6 \mathrm{hr}$ ), and precipitation of chitosan from the extract at $\mathrm{pH}$ 9.0, adjusted with $4 \mathrm{M} \mathrm{NaOH}$ solution. Chitosan was washed on a coarse sintered glass funnel (G-4) with water, ethanol, and acetone and air-dried at $20^{\circ} \mathrm{C}$.

The chitosans obtained from the crab shells and the fungi were characterised using fouriertransform infrared spectroscopy (FTIR) a Shimadzu IR-Prestige 21. The materials were made into pellets with $1 \% \mathrm{KBr}$ (Kaban, 2007).

The degree of deacetylation (DD) was calculated from FTIR spectra using the baseline method of Domszy and Rovert (Khan et al., 2002). The absorbance value was calculated using the formula:

$$
\mathrm{A}=\log \left(\mathrm{P}_{0} / \mathrm{P}\right)
$$

$\mathrm{P}_{0}: \%$ transmittance at a minimum peak. P:\% transmittance on the baseline. A comparison between absorbance at $\mathrm{A}=1655 \mathrm{~cm}^{-1}$ (amide band absorption 1) with absorbance at $A=3450 \mathrm{~cm}^{-1}$ (hydroxyl group uptake) was calculated. The chitin N-deacetylation $(100 \%)$ obtained from absorbance value at $1655 \mathrm{~cm}^{-1}$ was 1.33 . The degree of N-deacetylation can be calculated by:

$$
\% \text { N-deacetylation }=1-\frac{\mathrm{AA} 1655}{\mathrm{AA} 3450 \times 1.33} \times 100
$$

A1655: Absorbance at a wavelength of $1588 \mathrm{~cm}^{-1}$ amide/acetamide for group absorption. A3450: Absorbance at $3410 \mathrm{~cm}^{-1}$ hydroxyl $(\mathrm{OH})$ wavelength.

The chitosans were also characterised in terms of colour, particle-size, odour and $\mathrm{pH}$. Colour was determined visually, particle-size was based on feel, while odour was based on smell. The $\mathrm{pH}$ was determined in a 1:1 soil-to-water suspension.

Inhibition Test of Growth of $G$. boninense by $S$. racemosum's Chitosan (FuCsSr), $R$. arrhizus's Chitosan (FuCsRa) and Crab Shell's Chitosan and Antagonistic Test with S. racemosum and $R$. arrhizus Fungi

The inhibitory test had 11 treatments in a complete randomised design with three replications. The treatments were: Control (without treatment); media containing chitosan crab shell (CrCs) at 5000, 
7500 and 10000 ppm; media containing chitosan R. arrhizus (FuCsRa) at 5000, 7500, 10000 ppm; media containing chitosan S. rasemosum (FuCsSr) at 5000, 7500, 10000 ppm and antagonist test with $S$. racemosum and $R$. arrhizus.

Dextrose agar media with FuCsSr, FuCsRa and $\mathrm{CrCs}$ were made by dissolving FuCs and CrCs. The FuCS solution was made in $1 \%$ (v/v) acetic acid and added to the PDA ( $\mathrm{pH}$ adjusted to 5.6 with $\mathrm{NaOH}$ $30 \%(\mathrm{~b} / \mathrm{v})$ to obtain a final FuCsSr and FuCsRa concentration of 5000, 7500 and 10000 ppm (Berger et al., 2018).

Inhibitory tests were carried out by growing G. boninense on chitosan-treated media, and also on petri dishes with $S$. racemosum and $R$. arrhizus isolates. Isolated $S$. racemosum and $R$. arrhizus were placed at a distance of $1 \mathrm{~cm}$ from the edge of the petri dish the G. boninense colony was cultured on the opposite side with a distance of $1 \mathrm{~cm}$ from the edge of the petri dish. All isolates were obtained from their respective cultures using cork borer with a diameter of $4.3 \mathrm{~mm}$. The plates were incubated at room temperature. The antagonistic ability calculation used the inhibition zone formula. Observations were made at 1 day, 2 days, and 3 days after inoculation (DAI) on the inhibitory ability by measuring the areas of Ganoderma colonies using the formula $\mathrm{A}=2 \pi \mathrm{r}^{2}$, where $\mathrm{A}=$ area; $\mathrm{r}=$ radius of Ganoderma colony.

\section{RESULTS AND DISCUSSION}

\section{Chitosan Production from Crab Shells, $S$. racemosum and $R$. arrhizus}

The characterisation of chitosan extracted from crab shells, S. racemosum, and $R$. arrhizus using FTIR is shown in Figures 1-3. Most amide groups were converted into amine groups through the deacetylation process. The specific wavenumber at $1647.21 \mathrm{~cm}^{-1}$ in $\mathrm{CrCs}$ and both FuCs was the absorption of the $\mathrm{C}=\mathrm{O}$ amide group left from chitin, indicating the presence of an acetyl group, which was reduced due to the process. The uptake of the methyl group $\left(-\mathrm{CH}_{3}\right)$ at wavenumber $1435.04 \mathrm{~cm}^{-1}$ confirmed the presence of an amide group from chitin (Puspawati and Simpen, 2010). Wavenumber $3437.15 \mathrm{~cm}^{-1}$ indicated that the absorption of $\mathrm{O}-\mathrm{H}$ was overlapping with $-\mathrm{NH}_{2}$ from amines. Flap $-\mathrm{NH}_{2}$ absorption band and twist at $894.97 \mathrm{~cm}^{-1}$ confirmed that chitosan had been formed (Figures 1-3).

The chitosan FTIR characterisation showed mixed results in all aspects of character testing. The chitosan was extracted from various sources showed diverse results. The best quality chitosan was extracted from S. racemosum with $52.50 \%$ deacetylation value and the lowest was from $R$. arrhizus which was $29.10 \%$ (Table 1).

Characterisation of chitosan was carried out including colour, particle-size, aroma, $\mathrm{pH}$ and deacetylation degree. The results showed that chitosan with chitin deacetylation had a similar physical appearance. The differences were only apparent in the number of parameters. The extracted chitosans had a fine powder texture and coarse powder texture. The chitosan extracted from the crab shells gave out odour while chitosans extracted from the fungi were odourless. The $\mathrm{pH}$ level of all chitosans was alkaline with a value between 11.7 to 12.7 and had a degree of deacetylation of $29.10 \%$ up to $52.50 \%$ (Table 2).

Chitosans extracted from the crab shell, $S$. racemosum and $R$. arrhizus had similar characteristics (Kumar, 2000). The readings using FTIR showed the results of different deacetylation degrees of each chitosan. The results showed that the chitosan from crustacean and chitosans from fungi were very different. The deacetylation process causes chitosan to contain

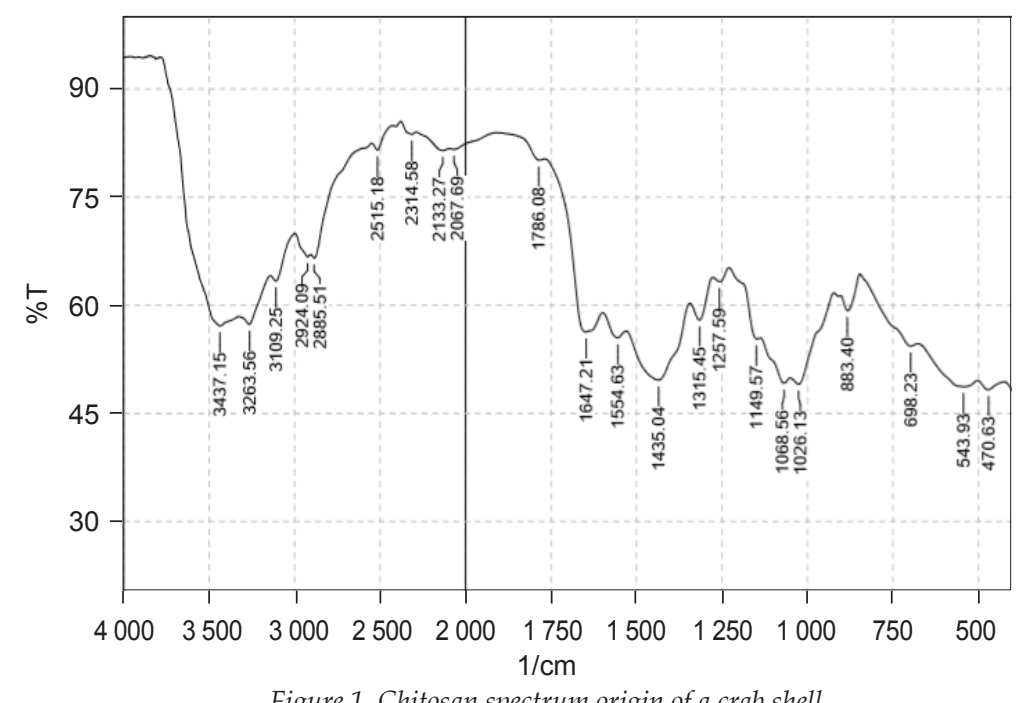

Figure 1. Chitosan spectrum origin of a crab shell. 


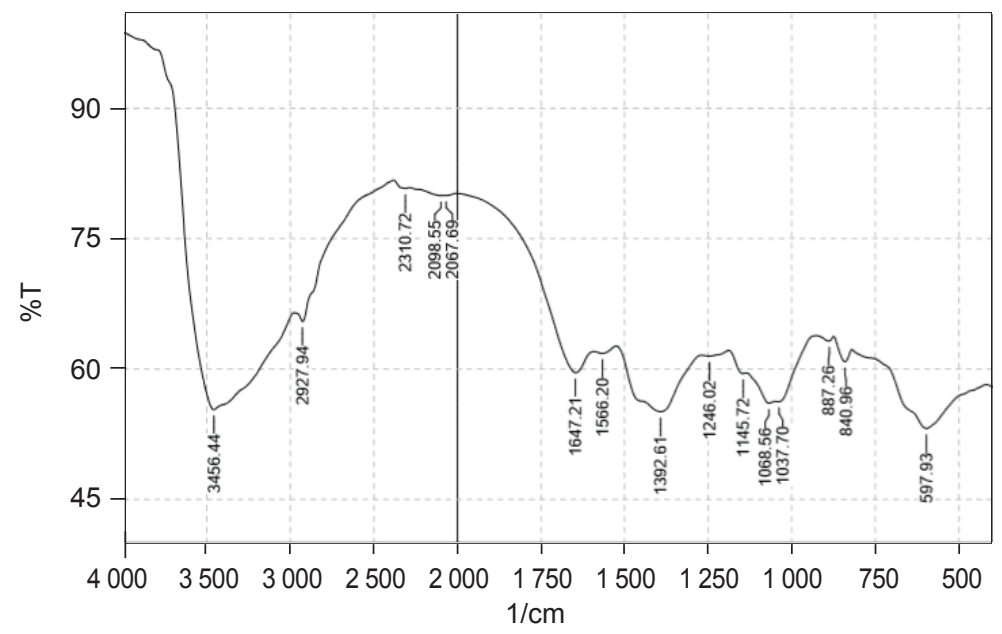

Figure 2. Chitosan spectrum origin of S. racemosum.

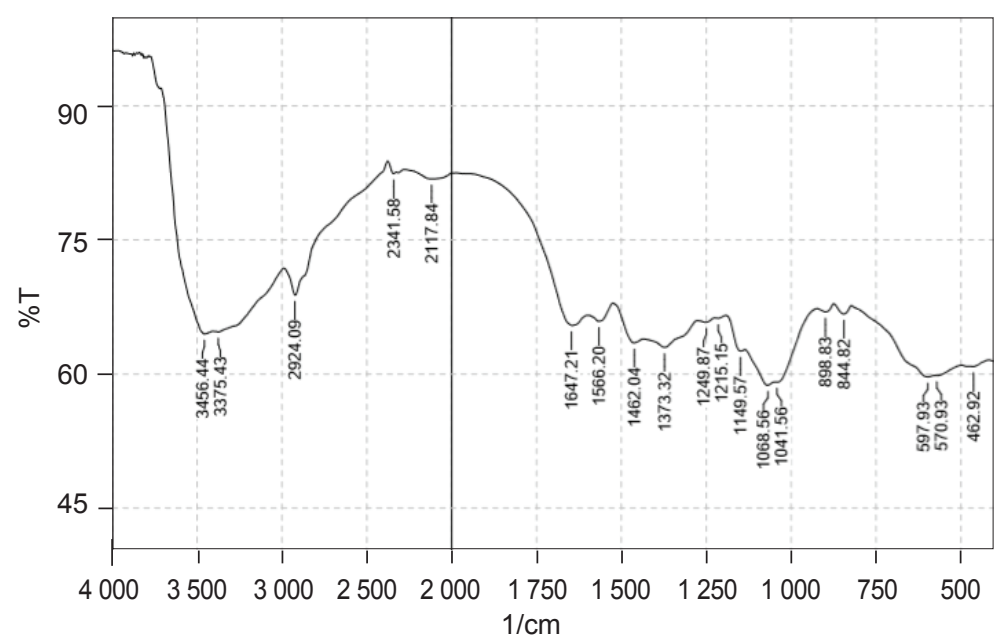

Figure 3. Chitosan spectrum origin of R. arrhizus.

TABLE 1. CHARACTERISATION OF CHITOSAN FTIR SPECTRUM OF CRAB SHELL, S. rasemosum AND R. arrhizus

\begin{tabular}{|c|c|c|c|c|c|}
\hline \multirow{2}{*}{ No. } & \multirow{2}{*}{ Vibration modes } & \multicolumn{4}{|c|}{ Wavelength $\left(\mathrm{v} \mathrm{cm}^{-1}\right)$} \\
\hline & & Standard chitosan* & Crab shell & S. rasemosum & R. arrhizus \\
\hline 1 & $\begin{array}{l}v(\mathrm{NH} 2) \text { assoc. in primary amines } \\
v(\mathrm{OH}) \text { assoc. in pyranose ring }\end{array}$ & 3377.95 & 3437.15 & 3456.44 & 3456.44 \\
\hline 2 & (vb) C-H Aliphatic & 2922.85 & 2924.09 & 2927.94 & 3375.43 \\
\hline 3 & (vs) C-H Aliphatic & 2922.80 & 2885.51 & 2310.72 & 2924.09 \\
\hline 4 & (vs) C-H Aromatic & 2361.41 & 2314.58 & 2098.56 & 2431.58 \\
\hline 5 & (v) $\mathrm{C}=\mathrm{H}$ Amide I band & 1660.55 & 1647.21 & 1647.21 & 1647.21 \\
\hline 6 & (v) $\mathrm{C}=\mathrm{H}$ ) Amide II band amide II band & 1587.94 & 1554.63 & 1566.20 & 1566.20 \\
\hline 7 & (v) C-H & 1422.73 & 1435.04 & 1392.61 & 1462.04 \\
\hline 8 & (vs) $\mathrm{C}-\mathrm{O}$ & 1259.54 & 1257.59 & 1246.02 & 1249.87 \\
\hline 9 & (vs) $\mathrm{C}-\mathrm{O}$ & 1154.64 & 1149.57 & 1145.72 & 1149.57 \\
\hline 10 & $\mathrm{v}(\mathrm{C}-\mathrm{O}-\mathrm{C})$ & 1077.93 & 1068.56 & 1068.56 & 1068.56 \\
\hline 11 & $\mathrm{v}(\mathrm{C}-\mathrm{O}-\mathrm{C})$ & 1026.63 & 1026.13 & 1037.70 & 1041.56 \\
\hline 12 & $\omega \beta$-1,4-glikosidik & 897.41 & 883.40 & 887.26 & 898.83 \\
\hline
\end{tabular}

Source: Dompeipen (2017).

amine and hydroxyl groups, which have high chemical reactivity (Adriana et al., 2001). Amine groups can be used immediately in chemical reactions to form salts and acids, for example, with calcium $\left(\mathrm{Ca}^{2+}\right)$, phosphate $\left(\mathrm{PO}_{4}^{3-}\right)$, sodium $\left(\mathrm{Na}^{+}\right)$and several other elements (Sanford, 1989). Stretching vibration at wave number $1647.21 \mathrm{~cm}^{-1}$ is an absorption band of $\mathrm{C}=\mathrm{O}$ bond group, which 
shows the presence of a secondary amine group, while the absorption band of 3437.15 and $3456.44 \mathrm{~cm}^{-1}$ is a vibration of the $\mathrm{OH}$ and $\mathrm{NH}_{2}$ groups. This absorption band pattern was the same as that of the standard chitosan spectrum, namely at wavenumbers 1660.55 and $2922.85 \mathrm{~cm}^{-1}$. One characteristic absorption for chitosan compounds is the presence of weak stretch absorption in the area of $1650 \mathrm{~cm}^{-1}$ which indicates the presence of a $\mathrm{C}=\mathrm{O}$ group on the bond $\left(-\mathrm{NHCOCH}_{3}\right)($ Silverstein et al., 1981) The absorption bands at 2885.51, 2927.94 and $2924.09 \mathrm{~cm}^{-1}$ in the extracted chitosans and $2922.85 \mathrm{~cm}^{-1}$ in standard chitosan showed symmetrical stretching vibration of $\mathrm{C}-\mathrm{H}$ bonds. The absorption bands at wavenumber 1554.63, 1566.20, and $1566.20 \mathrm{~cm}^{-1}$ showed that there was a stretching vibration of the $\mathrm{C}=\mathrm{O}$ bond, which indicated the presence of carbonyl groups. The standard chitosan spectrum also shows absorption in the same wavenumber area of $1587.94 \mathrm{~cm}^{-1}$ (Dompeipen, 2017).

TABLE 2. CHARACTERISATION OF CHITOSANS

\begin{tabular}{llll}
\hline \multirow{2}{*}{ Characteristics } & \multicolumn{3}{c}{ Source of chitosan } \\
\cline { 2 - 4 } & Crab shells & R. arrhizus & S. racemosum \\
\hline Colour & White & Black & Dark green \\
Texture & Smooth & $\begin{array}{c}\text { Coarse } \\
\text { powder }\end{array}$ & $\begin{array}{c}\text { Coarse } \\
\text { powder }\end{array}$ \\
Aroma & Odour & Odour less & Odour less \\
pH & 12,7 & 11,7 & 11,7 \\
DD & $43.00 \%$ & $29.10 \%$ & $52.50 \%$ \\
\hline
\end{tabular}

Note: DD - degree of deacetylation.

Based on the analysis of the infrared spectrum characteristics compared to standard chitosan, there was no significant difference between the two spectra. The presence of the main spectrum in certain wavelength regions indicates the presence of a major functional group, which indicates that the compound from the deacetylation reaction is chitosan (Dompeipen, 2017). The characteristic that strengthens the formation of chitosan was characterised by the appearance of wave absorption bands, which were formed at a vibration stretching wave between 3550 and $1655 \mathrm{~cm}^{-1}$. The length of absorption of the waveband indicated the presence of secondary amide groups and $\mathrm{OH}$ and $\mathrm{NH}$ groups. The loss of the methyl $\left(\mathrm{CH}_{3}\right)$ group bound to amide $\left(\mathrm{NHCOCH}_{3}\right)$ could be seen from the loss of absorption at wavenumber $2982.65 \mathrm{~cm}^{-1}$ and the loss of group $\mathrm{C}=\mathrm{O}$ an amide (NHCO) known from the loss of absorption band at wavenumber $1670.35 \mathrm{~cm}^{-1}$. The typical absorption of chitosan at wavenumber $1666.30 \mathrm{~cm}^{-1}$ shows the vibration stretching of $\mathrm{N}-\mathrm{H}$ from amide (Silverstein et al., 1981).

\section{Ganoderma Growth Inhibition Test}

The in vitro inhibitory test on 1, 2 and 3 DAI showed different results in the suppression of Ganoderma growth. The incubation test at 1 and 2 DAI showed that $R$. arrhizus was the best treatment in suppressing the growth of Ganoderma. Incubation test in 3 DAI showed different results, namely, the treatment with $S$. racemosum inoculation was the best treatment. The incubation results in 3 DAI were not significantly different from the direct treatment of $R$. arrhizus inoculation (Table 3 ).

The addition of chitosan from crab shells increased the development of $G$. boninense. CrCs concentration of $10000 \mathrm{ppm}$ in the media resulted in increased growth of $G$. boninense 1.57 times compared to control. This result warrants careful consideration on the source of chitosan for use in G. boninense treatment.

Chitosan from $S$. racemosum suppressed G. boninense development, but there was no difference in the effect of different concentrations. Chitosan as an antifungal material produced by $R$. arrhizus and S. racemosum could affect the growth

TABLE 3. TEST FOR INHIBITION ON GROWTH OF G. boninense

\begin{tabular}{|c|c|c|c|c|c|c|}
\hline \multirow{3}{*}{$\begin{array}{l}\text { Treatments } \\
\text { Control }\end{array}$} & \multicolumn{6}{|c|}{ Development of G. boninense colony area $\left(\mathrm{mm}^{2}\right)$} \\
\hline & \multicolumn{2}{|c|}{1 day } & \multicolumn{2}{|c|}{2 days } & \multicolumn{2}{|c|}{3 days } \\
\hline & 4.97 & $\mathrm{ab}$ & 10.20 & $a b$ & 16.20 & $\mathrm{~cd}$ \\
\hline CrCs 5000 ppm & 4.83 & $\mathrm{abc}$ & 9.63 & bc & 12.53 & de \\
\hline CrCs 7500 ppm & 5.03 & a & 10.57 & $\mathrm{ab}$ & 21.47 & $\mathrm{ab}$ \\
\hline CrCs 10000 ppm & 4.90 & $a b c$ & 13.13 & $\mathrm{a}$ & 25.47 & $\mathrm{a}$ \\
\hline FuCsRa 5000 ppm & 4.53 & $\mathrm{~cd}$ & 7.70 & bc & 12.43 & de \\
\hline FuCsRa 7500 ppm & 4.43 & $\mathrm{~d}$ & 10.07 & $\mathrm{~b}$ & 16.17 & $\mathrm{~cd}$ \\
\hline FuCsRa 10000 ppm & 4.63 & bcd & 9.53 & bc & 19.73 & bc \\
\hline FuCsSr 5000 ppm & 5.07 & $\mathrm{a}$ & 8.40 & bc & 11.50 & de \\
\hline FuCsSr 7500 ppm & 5.03 & a & 7.90 & bc & 11.13 & de \\
\hline FuCsSr 10000 ppm & 4.63 & bcd & 9.07 & bc & 11.40 & de \\
\hline Antagonist test $S$. racemosum & 4.73 & abcd & 7.73 & bc & 9.23 & $\mathrm{e}$ \\
\hline Antagonist test $R$. arrhizus & 4.43 & $\mathrm{~d}$ & 6.37 & $\mathrm{c}$ & 10.13 & e \\
\hline
\end{tabular}

Note: The number followed by the same letter in the same column is not significantly different according to the Duncan test at a $5 \%$. 
of Ganoderma. This is in line with the research of Berger et al. (2018), which stated that Mucolares fungi naturally produce chitin and FuCS on their cell walls during their growth through the action of chitin deacetylase enzymes, which catalyse chitin deacetylation to form chitosan.

Basically, Ganoderma does have slightly slower growth. But in this experiment, the growth of the treated Ganoderma had slower growth than control. The results of secondary metabolism produced from the fungi $R$. arrhizus and $S$. racemosum affected the growth system of Ganoderma. El Ghaouth et al. (1997) reported that chitosan inhibits the growth of in vitro of most postharvest pathogens. Chitosan was also reported to inhibit the proliferation of Botrytis cinerea, causal fungus that damages and stimulates cellular changes in Rhizopus stolonifer and B. cinerea. The treatment of chitosan was also reported to cause pathogenic hyphae to undergo cellular disorganisation that ranges from the decomposition of cell walls to cytoplasmic disintegration.

\section{CONCLUSION}

Chitosan has a fine to a coarse powder particlesize with white, black, dark green colour with a $\mathrm{pH}$ ranging from 11.7-12.7. All types of chitosan from this experiment have a purity level (degree of deacetylation) of $29.10 \%-52.50 \%$. Chitosan can be extracted from fungi found in chipped oil palm trunks.

Chitosan from $S$. racemosum at concentrations of 5000, 7500 and 10000 ppm were able to inhibit the growth of Ganoderma ( $-28 \%$ to $-31 \%)$, similar to the ability of well-known antagonists $R$. arrhizus $(-37 \%)$ and S. racemosum $(-43 \%)$. The results of this study indicated that the application of FuCsSr and $S$. racemosum had a significant effect in inhibiting the growth of Ganoderma in vitro, therefore it is recommended to carry out a test in the field.

\section{ACKNOWLEDGEMENT}

The authours would like to thank the DirectorGeneral of MPOB for permission to publish the article.

\section{REFERENCES}

Adriana, A; Mudjiajati, E; Selvy, V and Setijawati (2001). Adsorbs Cr (IV) with chitosan adsorbent. Environmental Chemistry, 3: 31-36.

Amorim, R V S; Melo, E S; Carneiro-da-Cunha, M G; Ledingham, W M and Campos-Takaki, G M (2003). Chitosan from Syncephalastrum racemosum used as a film support for lipase immobilization. Bioresour. Technol., 89(1): 35-39.

Berger, L R R; Stamford,T C M; de Oleveira, K A R; Pessoa, A M P; de Lima, M A B; Pintado, M M E; Camara M P S; Franco L O; Camara, M P S; Franco, L O; Magnani, M and de Souza, E L (2018). Chitosan produced from Mucorales fungi using agroindustrial by-products and its efficacy to inhibit Colletotrichum species. Int. J. Biological Macromol., 108: 635-641.

Dompeipen, E J (2017). Isolation and identification of chitin and chitosan from shrimp skin (Penaeus monodon) with infrared spectroscopy. Industrial Research and Standardization Center Ambon. J. Ministry of Industry. e-ISSN: 2548-4842 p-ISSN: 02151464.

El Ghaouth, A; Arul, J; Wilson, C and Benhamou, N (1997). Biochemical and cytochemical aspects of the interactions of chitosan and Botrytis cinerea in bell pepper fruit. Postharvest Biol. Technol., 12(2): 183-194.

Kaban, J (2007). Characteristic Study and Application of Alginate-Chitosan Alkali Metal Coating. Ph.D thesis, Universitas Sumatera Utara Medan. 271 pp.

Khan, T A; Peh, KK and Chang, HS (2002). Reporting degree of deacetylation values of chitosan: The influence of analytical methods. J. Pharm. Sci., 5(3): 205-212.

Kumar, M N V R (2000). A review of chitin and chitosan applications. React. Funct. Polym., 46(1): 1-27.

Puspawati and Simpen (2010). Optimization of chitin deacetylation of shrimp shells and crab shells of seafood restaurant waste became chitosan through variations in $\mathrm{NaOH}$ concentration. Chemical Journal, 4(1): 79-90.

Sabrina, T; Poltak and Hanafiah, A S (2018). Five fungus originated from oil palm trunk: Type and potency. Proc. of the National Seminar. 27 January 2018. University Mataram Lombok, Indonesia.

Sanford, P A (1989). Chitosan: Commercial uses and potential application. Chitin and Chitosan. p. 51-59.

Silverstein, R M; Francis, X W and David, J K (1981). Spectrometric identification of organic compound. John Wiley and Sons. 550 pp.

Synowiecki, J and Al-Khateeb, N A A Q (1997). Mycelia of Mucor rouxii as a source of chitin and chitosan. Food Chem., 60(4): 605-610. 